\title{
Reductive dehalogenation as a respiratory process
}

\author{
Christof Holliger \& Wolfram Schumacher \\ Swiss Federal Institute for Environmental Science and Technology (EAWAG), Limnological Research Center, \\ CH-6047 Kastanienbaum, Switzerland
}

Key words: chlorinated compounds, dechlorination, bacteria, anaerobic respiration, co-metabolism, biodegradation

\begin{abstract}
Anaerobic bacteria can reductively dehalogenate aliphatic and aromatic halogenated compounds in a respiratory process. Only a few of these bacteria have been isolated in pure cultures. However, long acclimation periods, substrate specificity, high dehalogenation rates, and the possibility to enrich for the dehalogenation activity by subcultivation in media containing an electron donor indicate that many of the reductive dehalogenations in the environment are catalyzed by specific bacteria. Molecular hydrogen or formate appear to be good electron donors for the enrichment of such organisms. Furthermore, systems have to be employed which supply the cultures with the halogenated compounds beyond their toxicity level. All bacteria that are presently available in pure culture and grow with a halogenated compound as electron acceptor are members of new genera. Based on experimental results with the membrane-impermeable electron mediator methyl viologen, a model of the respiration system of Dehalobacter restrictus, a tetrachloroethene-dechlorinating bacterium, is presented. Further studies of the biochemistry and energetics of respiratory-dehalogenating strains will help to understand the mechanisms involved and perhaps reveal the evolutionary origin of the dehalogenating enzyme systems.
\end{abstract}

Abbreviations: PCE - tetrachloroethene, TCE - trichloroethene, cis-1,2-DCE - cis-1,2-dichloroethene, PCER tetrachloroethene reductase

\section{Introduction}

For many halogenated compounds, reductive dehalogenation is the initial step in anaerobic biodegradation. Although reductive dehalogenation has been reported for a large variety of aliphatic and aromatic compounds (extensively reviewed by Kuhn \& Suflita 1989 and Mohn \& Tiedje 1992), only little is known about the organisms involved. It can be concluded from our present knowledge that some anaerobic bacteria catalyze reductive dehalogenations in a co-metabolic process whereas others dehalogenate in a respiratory process (Holliger 1992; Holliger \& Schraa 1994; Mohn \& Tiedje 1992). In the co-metabolic process, dehalogenations are not coupled to energy conservation and are unspecifically carried out in a bypass reaction by certain enzyme systems. The redox potential of redox couples such as tetrachloroethene (PCE)/trichloroethene (TCE) $\left(\mathrm{E}_{H}^{0 \prime}=485 \mathrm{mV}\right.$; calculated from Gibbs free ener- gy of formation data from Dolfing \& Janssen 1994) and 3-chlorobenzoate/benzoate $\left(\mathrm{E}_{H}^{0 \prime}=297 \mathrm{mV}\right.$; Dolfing \& Harrison 1992) is quite positive and makes these compounds potential electron acceptors for bacterial growth. Some bacterial cultures that grow with molecular hydrogen, formate, and acetate as electron donor and a halogenated compound as terminal electron acceptor apparently couple reductive dehalogenation to electrogenic energy conservation. Although the mechanism of energy conservation is presently not known, we will refer to these organisms as respiratorydehalogenating bacteria. Four pure cultures of anaerobic bacteria which dechlorinate an aromatic compound have been described to date (Cole et al. 1992; DeWeerd et al. 1990; Madsen \& Licht 1992; Tsuchiya \& Yamaha 1984). Desulfomonile tiedjei, a 3-chlorobenzoatedechlorinating bacterium, is the first anaerobic bacterium described that uses a chlorinated compound as electron acceptor in an anaerobic respiration process 
(DeWeerd et al. 1990; Dolfing 1990; Mohn \& Tiedje 1990; Mohn \& Tiedje 1991). A 2-chlorophenoldechlorinating bacterium appears to have similar physiological properties (Cole et al. 1992) whereas the physiological meaning of the dechlorination reaction is not known for another chlorophenol- (Madsen \& Licht 1992) and a chlorobenzene-dechlorinating (Tsuchiya \& Yamaha 1984) strain. For an almost endless list of halogenated aromatic compounds which were reductively dehalogenated in environmental samples, the bacteria involved could not yet be identified. Contrary to aromatic compounds, many pure cultures of anaerobic bacteria are reported to dehalogenate aliphatic compounds. Dehalobacter restrictus and Dehalospirillum multivorans, both isolated with PCE as electron acceptor (Holliger 1992; Neumann et al. 1994), are two respiratory-dehalogenating bacteria. Many others such as methanogens, acetogens, sulfate-reducers, and iron-reducers catalyze co-metabolic reactions with no benefit for the organism (Belay \& Daniels 1987; Castro et al. 1985; Criddle et al. 1990; Egli et al. 1987; Egli et al. 1988; Fathepure et al. 1987; Gälli \& McCarty 1989; Holliger et al. 1990; Jagnow \& Haider 1977; MacRae et al. 1969; Mikesell et al. 1990; Picardal et al. 1993). There are still reductive dehalogenations of aliphatic compounds which were observed in environmental samples to which no bacterium can as yet be ascribed, e.g. the dechlorination of dichloroethenes and vinyl chloride. In an excellent and detailed review, Mohn $\&$ Tiedje (1992) summarized two years ago what was known about the different aspects of reductive dehalogenation. They focused their review on ecological and physiological principles which began to emerge from a broad perspective of reductive dehalogenation. The scope of this review is to summarize the information published in the meantime with special emphasis on reductive dehalogenation as a respiratory process.

\section{Dehalogenation by anaerobic mixed cultures}

Anaerobic bacteria can be involved in reductive transformation of organic pollutants either directly by enzymatic processes or indirectly by microbially-produced bulk reductants such as reduced iron and sulfur species (Macalady et al. 1986). In the latter case, the reaction can be accelerated by the action of electron mediators such as quinones and metal porphyrins (Schwarzenbach et al. 1990) or in the presence of mineral surfaces (Heijman et al. 1994; Kriegman-King \& Reinhard 1992). Inactivation of biological activity by auto- claving, the most often applied technique, cannot distinguish between the direct and indirect involvement of bacteria. However, acclimation periods and substrate specificities of different cultures which are often observed, and enrichment of dehalogenating activity with electron donors indicate that specific enzymatically-dehalogenating bacteria are responsible for the reductive dehalogenations found in environmental samples (Mohn \& Tiedje 1992). Similar to dechlorination of many other aromatic compounds (Mohn \& Tiedje 1992) also with chlorobenzenes long lag periods of five to ten weeks were observed before dechlorination started in batch cultures inoculated with Rhine River sediments (Holliger et al. 1992) or soil (Ramanand et al. 1993). Such long acclimation periods can be explained only by phenomena such as adaptation on the genetic level or slow growth of specific bacteria. Chlorobenzenes were dechlorinated via distinct pathways. Depending on the source of the environmental sample, hexachlorobenzene was dechlorinated either to 1,3,5trichlorobenzene (Beurskens et al. 1994; Fathepure et al. 1988; Holliger et al. 1992; Mousa \& Rogers 1990) or 1,2,3-trichlorobenzene (Fathepure \& Vogel 1991; Mousa \& Rogers 1990; Ramanand et al. 1993) as major intermediate or end-product. 1,2,3-trichlorobenzene is dechlorinated exclusively to 1,2-dichlorobenzene by some cultures (Fathepure \& Vogel 1991; Mousa \& Rogers 1990; Ramanand et al. 1993), whereas other cultures formed only 1,3-dichlorobenzene (Beurskens et al. 1994; Bosma et al. 1988; Holliger et al. 1992). A 2,3,4-trichlorobiphenyl-dechlorinating enrichment culture obtained from sediment dechlorinated 2,4,5trichlorobiphenyl mainly to 2,4-dichlorobiphenyl with small amounts of 2,5-dichlorobiphenyl after the first transfer to 2,4,5-trichlorobiphenyl-containing medium (Rhee et al. 1993). However, with repeated transfer, the proportion of 2,5-dichlorobiphenyl increased, becoming the only product in the fifth transfer. Apparently, the dechlorinating culture had shifted from a meta- to a para-dechlorinating population. For enrichment and maintenance of dehalogenating activity by transfers, amendment of the cultures with an electron donor was necessary (DiStefano et al. 1992; Holliger et al. 1992; Holliger et al. 1993; Neumann et al. 1994). In many cultures in which enrichment of dehalogenation activity was possible, molecular hydrogen served as electron donor. Desulfomonile tiedjei obtained the reducing equivalents in the original 3-chlorobenzoate-degrading consortium from hydrogen produced upon oxidation of benzoate (Dolfing 
\& Tiedje 1986). The PCE-dechlorinating bacterium in a benzoate-oxidizing mixed culture probably was a hydrogen-scavenging organism as well (ScholzMuramatsu et al. 1990). Vancomycin, an inhibitor of cell wall synthesis in eubacteria, inhibited dechlorination of PCE in another mixed culture in which methanol was present as electron donor (DiStefano et al. 1992). The same inhibitor did not influence PCEdechlorination in the presence of hydrogen. Acetogenesis, the other methanol-or hydrogen-consuming process in this culture, was inhibited by vancomycin with either substrate. These results suggest that hydrogen is used directly for dechlorination in this culture by organisms resistant to vancomycin, and that acetogens metabolize part of the methanol to hydrogen. Apparently, respiratory-dehalogenating bacteria have to compete in methanogenic systems with other hydrogen-oxidizing bacteria such as methanogens and acetogens. Inhibiting methanogenic activity of anaerobic mixed cultures by the methanogen-specific inhibitor bromoethanesulfonic acid often did not influence dehalogenation (Holliger et al. 1992; Holliger et al. 1993; Scholz-Muramatsu et al. 1990). In a PCEdechlorinating mixed culture with negligible methane production prior to addition of the inhibitor, bromoethanesulfonic acid inhibited dechlorination (DiStefano et al. 1992). It was suggested that bromoethanesulfonic acid did not act as inhibitor of methanogens in this culture but as inhibitor of the PCE-dechlorinating system. Acetogenesis and methanogenesis both were absent in PCE-dechlorinating enrichment cultures with molecular hydrogen and carbon dioxide in the gas phase (Bowser et al. 1993; Holliger et al. 1993). Acetogens that were isolated from a 1,2,3-trichlorobenzenedechlorinating mixed culture which formed acetate but not methane on $\mathrm{H}_{2} / \mathrm{CO}_{2}$, were not able to dechlorinate 1,2,3-trichlorobenzene (Holliger et al. 1992). All these results indicate that acetogens and methanogens were not responsible themselves for the dechlorination reactions observed.

In addition, theoretical considerations on observed dechlorination rates in PCE-dechlorinating systems show that methanogens and acetogens are not the dechlorinating organisms in these systems (Table 1). PCE-dechlorination rates reported for Methanosarcina sp. or Acetobacterium woodii are as low as $3.5 \times 10^{-5}$ and $3.6 \times 10^{-3} \mu \mathrm{mol} / \mathrm{h}$ per $\mathrm{mg}$ protein, respectively. With a fixed-bed column and an enrichment culture, dechlorination rates as high as 3.7 and $11.5 \mu \mathrm{mol} / 1$ per $h$ were found, respectively. To explain these high rates by the activity of either Methanosarcina sp. or
A. woodii as model bacteria, unrealistically high concentrations of cells of 1 to $330 \mathrm{~g}$ protein/l would need to be present in the PCE-dechlorinating systems. Furthermore, the extent of dechlorination was different. The PCE-dechlorinating systems formed the halogen-free products ethene and ethane whereas Methanosarcina sp. or A. woodii dechlorinated PCE only to trichloroethene.

\section{Enrichment of respiratory-dehalogenating bacteria}

From research on the few respiratory-dechlorinating bacteria available in pure culture it can be concluded that these organisms have a limited spectrum of electron donors which support growth (see below). Substrates such as molecular hydrogen, formate, or acetate are probably the most promising electron donors for enrichment of such organisms. Furthermore, the enrichment of respiratory-dechlorinating bacteria depends on their affinity for the electron donor, e.g. molecular hydrogen, and the availability of the electron acceptor. Respiratory-dehalogenating bacteria appear to be slow-growing organisms with high affinities for the electron donors. Slow-growing bacteria with high substrate affinity can possibly out-compete fast-growing organisms in systems with low substrate concentration. Possible ways to create advantageous conditions for such bacteria are to use continuous systems with low concentrations of the electron donor (De Bruin et al. 1992), or to enrich on metabolic processes for which bacteria with a high substrate affinity have a competitive advantage. The obligately syntrophic hydrogen-producing oxidation of benzoate was apparently a good system for the enrichment of respiratory-dechlorinating bacteria (ScholzMuramatsu et al. 1990; Shelton \& Tiedje 1984). Desulfomonile tiedjei was isolated from a 3-chlorobenzoateoxidizing culture. In this culture, Desulfomonile tiedjei obtained the reducing equivalents from the benzoateoxidizing hydrogen-producing strain (Dolfing \& Tiedje 1986). In another benzoate-oxidizing mixed culture in which methanogenesis was inhibited by bromoethanesulfonic acid, PCE-dechlorinating activity could be enriched by providing PCE as electron acceptor (Scholz-Muramatsu et al. 1990).

Concerning the enrichment with a halogenated compound as terminal electron acceptor, two major problems have to be taken into account. The halogenated compound can be either toxic at saturat- 
Table 1. Theoretical content of Methanosarcina sp. or Acetobacterium woodii protein in PCE-dechlorinating systems necessary to explain observed dechlorination rates of these systems by the activity of either Methanosarcina sp. or Acetobacterium woodii.

\begin{tabular}{|c|c|c|c|c|c|}
\hline $\begin{array}{l}\text { Dechlorinating } \\
\text { bacterium/system }\end{array}$ & $\begin{array}{l}\text { Temperature } \\
\left({ }^{\circ} \mathrm{C}\right)\end{array}$ & $\begin{array}{l}\text { End } \\
\text { product }^{a}\end{array}$ & Rate $^{b}$ & $\begin{array}{l}\text { Theoretical protein } \\
\text { content }^{c}(g / l)\end{array}$ & Reference \\
\hline Methanosarcinasp. & 37 & TCE & $\begin{array}{c}3.5 \times 10^{-5} \\
\mu \mathrm{mol} / \mathrm{mg} \text { per h }\end{array}$ & & (Fathepure et al. 1987) \\
\hline Acetobacterium woodii & 30 & TCE & $\begin{array}{l}<3.6 \times 10^{-3} \\
\mu \mathrm{mol} / \mathrm{mg} \text { per } \mathrm{h}\end{array}$ & & (Egli et al. 1988) \\
\hline Fixed-bed column & 10 & ethene & $\begin{array}{l}3.7 \\
\mu \mathrm{mol} / \mathrm{l} \text { per h }\end{array}$ & $\begin{array}{l}106 \\
>1.03\end{array}$ & (De Bruin et al. 1992) \\
\hline Enrichment culture & 35 & ethene & $\begin{array}{l}11.5 \\
\mu \mathrm{mol} / \mathrm{l} \text { per } \mathrm{h}\end{array}$ & $\begin{array}{l}329 \\
>3.19\end{array}$ & (DiStefano et al. 1991) \\
\hline
\end{tabular}

${ }^{a} \mathrm{TCE}=$ trichloroethene.

${ }^{b}$ Rates were determined by measuring the decrease in PCE. Rates for Methanosarcinasp. and $A$. woodii are per mg of protein.

${ }^{c}$ The theoretical protein content was calculated by deviding the rate found in the system with the rate of the bacterial cultures. This results in protein content in $\mathrm{g} / \mathrm{l}$ in the dechlorinating systems. The first protein content is calculated based on dechlorination rates by Methanosarcina sp., the second (italic) is calculated for rates by A. woodii.

ing concentration in water or it is not sufficiently water-soluble to create advantageous conditions for respiratory-dehalogenating bacteria. The problem of toxicity can be solved by repeatedly feeding with small amounts of the halogenated compound (DiStefano et al. 1991, 1992) or to use a two-liquid-phase system in which the halogenated compound is mainly dissolved in a water-immiscible organic phase such as hexadecane (Holliger et al. 1992; Holliger et al. 1993). The two-liquid-phase system allows addition of large amounts of the halogenated compound to a batch culture. Secondly, the concentration in the water phase can be kept below the toxicity level. Finally, this technique guarantees continuous and sufficient supply of the halogenated compound to the water phase. Using the first method, a culture was enriched in which the electron balance demonstrated that $31 \%$ of consumption of the electron donor methanol was accounted for by dechlorination of PCE to ethene (DiStefano et al. 1991). The two-liquid-phase system was used to enrich for a 1,2,3-trichlorobenzene- and a PCEdechlorinating culture (Holliger et al. 1992, 1993). In a study with low water-soluble compounds such as polychlorinated biphenyls, volumetric rates were increased from 8.2 to $346 \mu \mathrm{mol} 2,3,6$-trichlorobiphenyl dechlorinated/l per $\mathrm{d}$ by periodic (daily) supplementation of the cultures with 2,3,6-trichlorobiphenyl (Boyle et al. 1993). Specific nutritional requirements seem to hamper the enrichment of respiratory-dehalogenating bacteria. Desulfomonile tiedjei could initially be cultivated only in a medium supplemented with $10 \%$ rumen fluid (Shelton \& Tiedje 1984). Later, rumen fluid could be replaced by culture fluid of Propionibacterium sp. and finally, Desulfomonile tiedjei grew in a defined medium containing a vitamin solution plus naphthoquinone and hemin (DeWeerd et al. 1990). Growth of the PCE-dechlorinating bacterium Dehalobacter restrictus depends on the presence of vitamins and yeast extract or peptone (Holliger 1992). All attempts to cultivate this bacterium in a defined medium have failed to date. PCE dechlorination by an anaerobic culture enriched on methanol could also be sustained with molecular hydrogen as electron donor (DiStefano et al. 1992). However, the activity could be transferred and maintained with hydrogen only if the medium was supplemented with filter-sterilized medium of the original enrichment culture on methanol. The methanolgrown culture apparently produced an as yet unidentified growth factor needed by the dechlorinating bacterium.

\section{Pure cultures of respiratory-dehalogenating bacteria}

Although a quite broad variety of anaerobic bacteria is known to dehalogenate aliphatic halogenated compounds, these will not be discussed here. Many of the dehalogenations catalyzed by these bacteria are co-metabolic and not coupled to a respiration pro- 
cess. At present, there are five pure cultures of bacteria described which were isolated specifically on their ability to dehalogenate, three with aromatic compounds (Cole et al. 1992; Madsen \& Licht 1992; Shelton \& Tiedje 1984) and two with PCE (Holliger 1992; Neumann et al. 1994). Desulfomonile tiedjei was the first bacterium isolated which coupled the reductive dehalogenation to growth (Dolfing 1990; Mohn \& Tiedje 1991). A complete summary of all the work done with this strain has been published by Mohn \& Tiedje (1992). Desulfomonile tiedjei grows with formate or molecular hydrogen as electron donor and 3-chlorobenzoate as electron acceptor, with doubling times of 8 to 10 days in a defined medium and of 45 to 46 days in a medium supplemented with culture fluid of Propionibacterium sp. It is not yet clear whether or not acetate can be utilized as electron donor. Growth with acetate and 3-chlorobenzoate was possible (Dolfing 1990), whereas acetate oxidation could not be coupled to sulfate reduction (DeWeerd et al. 1990). The dechlorination activity is inducible and membrane-associated (DeWeerd \& Suflita 1990). Experiments with respiratory inhibitors and imposed $\mathrm{pH}$ gradients indicated a chemiosmotic coupling of reductive dechlorination and ATP synthesis (Mohn \& Tiedje 1991). Physiological characterization and 16S rRNA sequence analysis suggested to assign Desulfomonile tiedjei as a member of a new genus of sulfate-reducing bacteria. A small Gram-negative rod was isolated with acetate as energy and carbon source and 2-chlorophenol as electron acceptor (Cole et al. 1992). Fumarate or oxygen could replace 2-chlorophenol. However, oxygen served as a replacement only at low concentration. Fermentative growth has, as of yet, not been observed. The dechlorination activity is specific to the ortho-position, and is inducible. Another chlorophenol-dechlorinating bacterium seems to dechlorinate by fortuitous activities (Madsen \& Licht 1992). Pyruvate was the best growthsupporting substrate and was fermented to almost equimolar amounts of acetate. Although chlorophenols were dechlorinated at high rates of up to $30 \mathrm{nmol} / \mathrm{min}$ per mg protein as in the case of 2,4,6-trichlorophenol, chlorophenol-dependent growth was not demonstrated. Therefore, the physiological meaning of these dechlorination reactions is not yet clear. Recently, two strains of bacteria have been isolated that utilize PCE as terminal electron acceptor (Holliger et al. 1993; Neumann et al. 1994). Both strains dechlorinate PCE stoichiometrically to cis-1,2-dichloroethene (cis-1,2-DCE) and couple this reaction to growth on electron donors such as molecular hydrogen or formate. Dehalobacter restric-

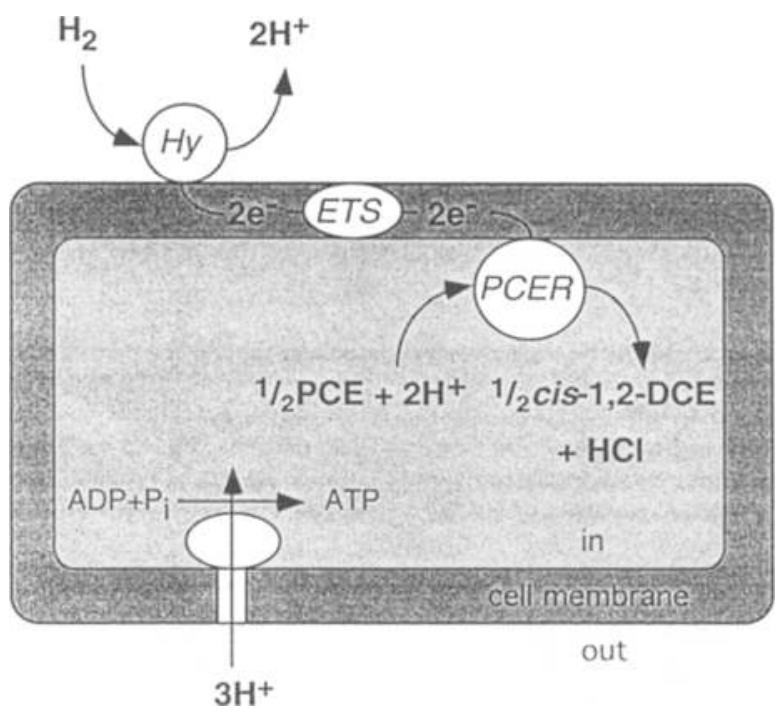

Fig. 1. Model of the respiration system of Dehalobacter restrictus. $H y=$ Hydrogenase, $E T S=$ Electron Transfer System, $P C E R=$ tetrachloroethene reductase, $\mathrm{PCE}=$ tetrachloroethene, $c i s-1,2-\mathrm{DCE}=$ cis-1,2-dichloroethene.

tus was isolated from an anaerobic fixed-bed column fed with lactate and PCE (Holliger 1992; Holliger et al. 1993). This bacterium has a very narrow substrate range which supports growth. Molecular hydrogen and PCE is the sole combination of electron donors and acceptors which allowed growth of Dehalobacter restrictus; fermentative growth was not found. Analysis of the 16S rRNA revealed that Dehalobacter restrictus is related to genera in the forth subdivision of Gram-positive bacteria (Holliger 1992). The other strain, Dehalospirillum multivorans, was isolated from activated sludge on a medium containing pyruvate plus PCE (Neumann et al. 1994). Contrary to Dehalobacter restrictus, Dehalospirillum multivorans utilizes several electron donors and acceptors. Pyruvate, formate and molecular hydrogen can serve as electron donor and PCE, fumarate, and elemental sulfur as electron acceptor. In the absence of an electron acceptor, fermentative growth on pyruvate was observed. With molecular hydrogen or formate as electron donor, growth was possible only if PCE or fumarate was present as electron acceptor. Both strains dechlorinate PCE at reasonably high rates and grow with doubling times of about one day. This makes these bacteria attractive candidates for studying the biochemistry and energetics of respiratory dehalogenations. 
Table 2. Hydrogenase and PCER activity of intact and lysed cells of Dehalobacter restrictus ${ }^{a}$.

\begin{tabular}{|c|c|c|}
\hline \multirow[t]{2}{*}{ Enzyme } & \multicolumn{2}{|c|}{$\begin{array}{l}\text { Specific activity } \\
\text { (nmol } \mathrm{H}_{2} / \text { min per mg protein) or } \\
\text { (nmol Cl}{ }^{-} / \text {min per } m g \text { protein) }\end{array}$} \\
\hline & Intact cells & Lysed cells \\
\hline $\begin{array}{l}\text { Hydrogenase } \\
\text { PCER }^{b}\end{array}$ & $\begin{array}{l}19 \pm 2 \\
32 \pm 3\end{array}$ & $\begin{array}{r}14 \pm 2 \\
183 \pm 20\end{array}$ \\
\hline $\begin{array}{l}{ }^{a} \text { The reaction } \\
0.4 \text { mM methyl } \\
\text { approx. } 0.13 \mathrm{~m} \\
\text { PCE (added fro } \\
\text { phase of the cu } \\
\text { If cells were ly } \\
\text { added to the re: } \\
(\mathrm{v} / \mathrm{v}) . \text { For PCEI } \\
\mathrm{PCE} \text { and the re } \\
\left(\epsilon=9.8 \mathrm{mM} \mathrm{M}^{-1}\right. \\
\text { hydrogenase ac } \\
\text { protein. } \\
b \text { PCER = tetra } \\
c \text { Two mole of } \\
\text { per mole of hyc } \\
\text { respectively. }\end{array}$ & $\begin{array}{l}\text { mixture conta } \\
\text { viologen for } \\
\mathrm{g} / \mathrm{ml} \text { cell prote } \\
\mathrm{m} \text { an anoxic } \mathrm{e} \\
\text { vettes was eith } \\
\text { sed with Tritor } \\
\text { ction mixture } \\
\text { activity, the } \\
\text { action followe } \\
\mathrm{cm}^{-1} \text { ) at } 30^{\circ} \\
\text { tivity was initi } \\
\text { chloroethene } \mathrm{r} \\
\text { methyl violog } \\
\text { lrogen consun }\end{array}$ & $\begin{array}{l}\text { CER } 50 \mathrm{mM} \text { Tris ( } \mathrm{pH} 8.0 \text { at } 30^{\circ} \mathrm{C} \text { ), } \\
\mathrm{CER} \text { and } 1 \mathrm{mM} \text { for hydrogenase, } \\
\text { hanol stock solution). The gas } \\
\text { 100\% hydrogen or nitrogen. } \\
\mathrm{X}-100 \text {, the detergent was } \\
\text { a final concentration of } 1 \% \\
\text { eaction was started by adding } \\
\text { spectrophotometrically at } 578 \mathrm{~nm} \\
\text { The measurement of } \\
\text { ted by the addition of cellular } \\
\text { ductase. } \\
\text { ed were reduced or oxidized }\end{array}$ \\
\hline
\end{tabular}

\section{Model of the respiration system of Dehalobacter restrictus}

Molecular hydrogen, the only electron donor utilized by Dehalobacter restrictus, cannot support substratelevel phosphorylation. Therefore, the energy of hydrogen oxidation must be conserved in a respiratory process. At least two enzymes are involved, a hydrogenase and a PCE reductase (PCER) catalyzing the following overall-reaction:

$\mathrm{PCE}+2 \mathrm{H}_{2} \rightarrow c i s-1,2-\mathrm{DCE}+2 \mathrm{H}^{+}+2 \mathrm{Cl}^{-} \quad \Delta \mathrm{G}^{\circ \prime}=-377.5 \mathrm{~kJ} / \mathrm{mol} \mathrm{PCE}$.

There are several possibilities how these two enzymes can be arranged in the bacterial cell. Either both the hydrogenase and the PCER can be on the outside or inside of the cell membrane or the hydrogenase can be on the outside and the PCER on the inside. There is experimental evidence for the latter arrangement as depicted in Fig. 1. Methyl viologen, an artificial electron for the hydrogenase and an artificial electron donor for the PCER (Holliger 1992), is membraneimpermeable in the oxidized as well as the reduced state (Jones \& Garland 1977). Hydrogenase activity was about the same with either intact cells and cells lysed by a Triton X-100 treatment (Table 2). On the contrary, PCER activity was increased by a factor of six after the Triton $\mathrm{X}-100$ treatment. This difference in accessibility of the enzymes by methyl viologen indicates that the hydrogenase is located on the outside of the cell membrane and the PCER is on the inside (Fig. 1). It is not known how the electrons are transferred between the two enzymes and whether a proton pump is coupled to the electron transfer. Dehalobacter restrictus contains menaquinones (Holliger 1992). Indication of the presence of cytochromes was not obtained by recording difference spectra of dithionite-reduced versus air-oxidized cell suspensions and cell extracts. Hence, menaquinone could be involved in the electron transfer. Cell yield considerations indicate that an additional proton pump is not involved. The low growth yield of $4.2 \mathrm{~g}$ dry mass per mole of chloride formed (Holliger et al. 1993) requires only 0.4 mole of ATP, assuming that one mole of ATP yields $10 \mathrm{~g}$ cell dry mass (Stouthamer 1979). The arrangement of the enzymes as depicted in Fig. 1 yields two protons outside the membrane upon formation of one chloride and the transport of two electrons. With the assumption that the formation of one ATP requires three protons, two-thirds of an ATP can thus be formed per chloride released, which is sufficient to explain the low growth yields. Therefore, no additional proton translocation across the membrane is needed if the hydrogenase and the PCER are arranged as indicated (Fig. 1). The possible influence of chloride transport across the membrane has not been taken into account in the model discussed above. PCE-dechlorination can be followed in cultures of Dehalobacter restrictus by measuring the increase in chloride concentration in the medium (Holliger et al. 1993). If the PCER is located inside the cell membrane, the chloride formed upon PCE-dechlorination has to be transported out of the cell. Chloride symport with a proton or a sodium both would increase the proton motive force. Sodium has first to be imported which probably occurs via a sodium-proton antiporter. Therefore chloride symport with a sodium results in a net efflux of a proton and a chloride ion. The influence of the excretion of end products of metabolic reactions on energy metabolism has recently been reviewed by Konings et al. (1994). Further characterization of the biochemistry and energetics of Dehalobacter restrictus will demonstrate whether the above assumptions are correct or whether this model needs to be modified. 


\section{Acknowledgements}

We are grateful to Anke Neumann, Heidrun ScholzMuramatsu, and Gabriele Diekert for allowing us to use data on Dehalospirillum multivorans prior to publication. Judith Perlinger and Alexander Zehnder are acknowledged for critically and carefully reading the manuscript.

\section{References}

Belay N \& Daniels L (1987) Production of ethane, ethylene, and acetylene from halogenated hydrocarbons by methanogenic bacteria. Appl. Environ. Microbiol. 53: 1604-1610

Beurskens JEM, Dekker CGC, Heuvel H van den, Swart M, Wolf J de \& Dolfing J (1994) Dechlorination of chlorinated benzenes by an anaerobic microbial consortium that selectively mediates the thermodynamic most favorable reactions. Environ. Sci. Technol. 28: 701-706

Bosma TNP, Meer JR van der, Schraa G, Tros ME \& Zehnder AJB (1988) Reductive dechlorination of all trichloro- and dichlorobenzene isomers. FEMS Microbiol. Lett. 53: 223-229

Bowser P, DiStefano T, Tandoi V, Gossett J \& Zinder SH (1993) Characterization of an anaerobic enrichment culture which rapidly converts tetrachloroethene to ethene. Abstr. Q194, p. 381, Abstr. 93rd Ann. Meet. Am. Soc. Microbiol. May 1993. American Society for Microbiology, Washington, D.C.

Boyle AW, Blake CK, Price WA \& May HD (1993) Effects of polychlorinated biphenyl congener concentration and sediment supplementation on rates of methanogenesis and 2,3,6trichlorobiphenyl dechlorination in an anaerobic enrichment. Appl. Environ. Microbiol. 59: 3027-3031

Bruin WP de, Kotterman MJJ, Posthumus MA, Schraa G \& Zehnder AJB (1992) Complete biological reductive transformation of tetrachloroethene to ethane. Appl. Environ. Microbiol. 58: 19962000

Castro CE, Wade RS \& Belser NO (1985) Biodehalogenation: Reactions of cytochrome $\mathrm{P}-450$ with polyhalomethanes. Biochemistry 24: 204-210

Cole JR, Foxworthy AL \& Tiedje JM (1992) Isolation and characterization of a bacterium growing by anaerobic reductive dehalogenation of 2-chlorophenol. Abstr. 9, p. 10. Abstr. ASM Conference Anaerobic Dehalogenation and Its Environmental Implications. September 1992, Athens, Georgia

Criddle CS, DeWitt JT \& McCarty PL (1990) Reductive dechlorination of carbon tetrachloride by Escherichia coli K-12. Appl. Environ. Microbiol. 56: 3247-3254

DeWeerd KA, Mandelco L, Tanner RS, Woese CR \& Suffita JM (1990) Desulfomonile tiedjei gen. nov. and sp. nov., a novel anaerobic, dehalogenating, sulfate-reducing bacterium. Arch. Microbiol. 154: 23-30

DeWeerd KA \& Suflita JM (1990) Anaerobic aryl reductive dehalogenation of halobenzoates by cell extracts of 'Desulfomonile tiedjei'. Appl. Environ. Microbiol. 56: 2999-3005

DiStefano TD, Gossett JM \& Zinder SH (1991) Reductive dechlorination of high concentrations of tetrachloroethene to ethene by an anaerobic enrichment culture in the absence of methanogenesis. Appl. Environ. Microbiol. 57: 2287-2292
- (1992) Hydrogen as an electron donor for dechlorination of tetrachloroethene by an anaerobic mixed culture. Appl. Environ. Microbiol. 58: 3622-3629

Dolfing J (1990) Reductive dechlorination of 3-chlorobenzoate is coupled to ATP production and growth in an anaerobic bacterium, strain DCB-1. Arch. Microbiol. 153:264-266

Dolfing J \& Harrison BK (1992) Gibbs free energy of formation of halogenated aromatic compounds and their potential role as electron acceptors in anaerobic environments. Environ. Sci. Technol. 26: $2213-2218$

Dolfing J \& Janssen DB (1994) Estimates of Gibbs free energies of formation of chlorinated aliphatic compounds. Biodegradation 5: $21-28$

Dolfing J \& Tiedje JM (1986) Hydrogen cycling in a threetiered food web growing on the methanogenic conversion of 3-chlorobenzoate. FEMS Microbiol. Ecol. 38: 293-298

Egli C, Scholtz R, Cook AM \& Leisinger T (1987) Anaerobic dechlorination of tetrachloromethane and 1,2-dichloroethane to degradable products by pure cultures of Desulfobacterium $\mathrm{sp}$. and Methanobacterium sp. FEMS Microbiol. Lett. 43: 257-261

Egli C, Tschan T, Scholtz R, Cook AM \& Leisinger T (1988) Transformation of tetrachloromethane to dichloromethane and carbon dioxide by Acetobacterium woodii. Appl. Environ. Microbiol. 54: 2819-2824

Fathepure BZ, Nengu JP \& Boyd SA (1987) Anaerobic bacteria that dechlorinate perchloroethene. Appl. Environ. Microbiol. 53: 2671-2674

Fathepure BZ, Tiedje JM \& Boyd SA (1988) Reductive dechlorination of hexachlorobenzene to tri- and dichlorobenzenes in anaerobic sewage sludge. Appl. Environ. Microbiol. 54: 327-330

Fathepure BZ \& Vogel TM (1991) Complete degradation of polychlorinated hydrocarbons by a two-stage biofilm reactor. Appl. Environ. Microbiol. 57: 3418-3422

Gälli R \& McCarty PL (1989) Biotransformation of 1,1,1trichloroethane, trichloromethane, and tetrachloromethane by a Clostridium sp. Appl. Environ. Microbiol. 55: 837-844

Heijman CG, Holliger C, Glaus MA, Schwarzenbach RP \& Zeyer J (1993) Abiotic reduction of 4-chloronitrobenzene to 4chloroaniline in a dissimilatory iron-reducing enrichment culture. Appl. Environ. Microbiol. 59: 4350-4353

Holliger C (1992) Reductive dehalogenation by anaerobic bacteria. PhD Thesis, Wageningen Agricultural University, Wageningen, The Netherlands

Holliger C \& Schraa G (1994) Physiological meaning and potential for application of reductive dechlorination by anaerobic bacteria. FEMS Microbiol. Rev. (in press)

Holliger C, Schraa G, Stams AJM \& Zehnder AJB (1990) Reductive dechlorination of 1,2-dichloroethane and chloroethane by cell suspensions of methanogenic bacteria. Biodegradation 1: 253261

Holliger C, Schraa G, Stams AJM \& Zehnder AJB (1992) Enrichment and propertics of an anacrobic mixed culture reductively dechlorinating 1,2,3-trichlorobenzene to 1,3-dichlorobenzene, Appl. Environ. Microbiol. 58: 1636-1644

- (1993) A highly purified enrichment culture couples the reductive dechlorination of tetrachloroethene to growth. Appl. Environ. Microbiol. 59: 2991-2997

Jagnow G \& Haider KEPC (1977) Anaerobic dechlorination and degradation of hexachlorocyclohexane isomers by anaerobic and facultative anaerobic bacteria. Arch. Microbiol. 115: 285-292

Jones RW \& Garland PB (1977) Sites and specificity of the reaction of bipyridylium compounds with anaerobic respiratory enzymes of Escherichia coli. Effects of permeability barriers imposed by the cytoplasmic membrane. Biochem. J. 164: 199-211 
Konings WN, Poolman B \& Veen HW van (1994) Solute transport and energy transduction in bacteria. Antonie van Leeuwenhoek (in press)

Kriegman-King MR \& Reinhard M (1992) Transformation of carbon tetrachloride in the presence of sulfide, biotite, and vermiculite. Environ. Sci. Technol. 26:2198-2206

Kuhn EP \& Suflita JM (1989) Dehalogenation of pesticides by anaerobic microorganisms in soils and groundwater - a review. In: Sawhnew BL \& Brown K (Eds) Reactions and Movement of Organic Chemicals in Soils (pp 111-180) Soil Science Society of America and American Society of Agronomy, Madison, Wisconsin, U.S.A.

Macalady DL, Tratnyek PG \& Grundl TJ (1986) Abiotic reduction reactions of anthropogenic organic chemicals in anaerobic systems: a critical review. J. Contam. Hydrol. 1: 1-28

MacRae IC, Raghu KL \& Bautista EM (1969) Anaerobic degradation of the insecticide lindane by Clostridium sp. Nature $221: 859-860$

Madsen T \& Licht D (1992) Isolation and characterization of an anaerobic chlorophenol-transforming bacterium. Appl. Environ. Microbiol. 158: 2874-2878

Mikesell MD, Boyd S \& A (1990) Dechlorination of chloroform by Methanosarcina strains. Appl. Environ. Microbiol. 56: 11981201

Mohn WW \& Tiedje JM (1990) Strain DCB-1 conserves energy for growth from reductive dechlorination coupled to formate oxidation. Arch. Microbiol. 153: 267-271

- (1991) Evidence for chemoosmotic coupling of reductive dechlorination and ATP synthesis in Desulfomonile tiedjei. Arch. Microbiol. 157: 1-6

- (1992) Microbial reductive dehalogenation. Microbiol. Rev. 56: 482-507

Mousa MA \& Rogers JE (1990) Dechlorination of hexachlorobenzene in two freshwater pond sediments under methanogenic conditions. Q-45, PG: 296, Abstr. Ann. Meet. Amer. Soc. Microbiol., Anaheim, CA, May
Neumann A, Scholz-Muramatsu H \& Diekert G (1994) Tetrachloroethene dechlorination to $c i s-1,2$-dichloroethene in cell suspensions and cell extracts of Dehalospirillum multivorans spec. nov. Abstr. P405, Frühjahrstagung der VAAM, March 1994, Hannover, Germany. BioEngineering 2/94: 82

Picardal FW, Armold RG, Couch H, Little AM \& Smith ME (1993) Involvement of cytochromes in the anaerobic biotransformation of tetrachloromethane by Shewanella putrefaciens 200. Appl. Environ. Microbiol. 59: 3763-3770

Ramanand K, Balba MT \& Duffy J (1993) Reductive dehalogenation of chlorinated benzenes and toluenes under methanogenic conditions. Appl. Environ. Microbiol. 59: 3266-3272

Rhee GY, Sokol RC, Bethoney CM \& Bush B (1993) Dechlorination of polychlorinated biphenyls by Hudson River sediment organisms: specificity to the chlorination pattern of congeners. Environ. Sci. Technol. 27: 1190-1192

Scholz-Muramatsu H, Szewzyk R, Szewzyk U \& Gaiser S (1990) Tetrachloroethylene as electron acceptor for the anaerobic degradation of benzoate. FEMS Microbiol. Lett. 66: 81-86

Scharzenbach RP, Stierli R, Lanz K \& Zeyer J (1990) Quinone and iron porphyrin mediated reduction of nitroaromatic compounds in homogeneous aqueous solution. Environ. Sci. Technol. 24: $1566-1574$

Shelton DR \& Tiedje JM (1984) Isolation and partial characterization of bacteria in an anaerobic consortium that mineralizes 3-chlorobenzoic acid. Appl. Environ. Microbiol. 48: 840-848

Stouthamer AG (1979) The search for correlation between theoretical and experimental growth yields. In: Quayle JR (Ed) International Review of Biochemistry, Microbial Biochemistry. (pp 1-47) Vol. 21. University Park Press, Baltimore, U.S.A.

Tsuchiya T \& Yamaha T (1984) Reductive dechlorination of 1,2,4trichlorobenzene by Staphylococcus epidermidis isolated from intestinal contents of rats. Agric. Biol. Chem. 48: 1545-1550 